\title{
Strengthening maternal and child health in China: Lessons from transforming policy proposals into action
}

\author{
Xiaoguang Yang ${ }^{1}$, Shenglan Tang ${ }^{2,3}$, Gavin Yamey ${ }^{2}$, Xu Qian ${ }^{1,4, *}$ \\ ${ }^{1}$ School of Public Health, Fudan University, Shanghai, China; \\ ${ }^{2}$ Duke Global Health Institute, Duke University, Durham, USA; \\ ${ }^{3}$ Global Health Research Center at Duke Kunshan University, Kunshan, China; \\ ${ }^{4}$ Global Heath Institute, Fudan University, Shanghai, China.
}

\begin{abstract}
Summary China has made impressive achievements in improving maternal and child health (MCH) over the past few decades. This paper uses a policy lens to examine reasons for these achievements as well as barriers to further success. We found that strong governmental commitment and leadership, effective coordination, proactive participation of different stakeholders, and the provision of adequate resources were associated with China's success in improving MCH outcomes. Other low- and middle-income countries can learn valuable lessons from China's experience. These lessons include $i$ ) prioritizing MCH on the national development agenda, ii) keeping national ownership over health development cooperation, and iii) establishing effective monitoring, evaluation and accountability mechanisms for MCH programs.
\end{abstract}

Keywords: Maternal and child health, policy implementation, enabling factors, China

\section{Introduction}

China has significantly improved its maternal and child health $(\mathrm{MCH})$ outcomes since the establishment of the People's Republic of China in 1949. Data available at the national level show that the key indicators of $\mathrm{MCH}$ in China have continually improved since the early 1990s (Table 1). From 1991 to 2013, China's under-five mortality rate fell by $80 \%$ and its maternal mortality ratio (MMR) fell by $71 \%(1)$.

These achievements are due largely to the country's rapid, sustained economic growth, the continuing enhancement of the MCH service delivery system (2), and, as we discuss in this paper, the effective development and implementation of health policies and strategies. In this paper, we attempt to distill lessons on implementing $\mathrm{MCH}$ strategies by taking an overarching policy view. Such lessons are based on decades of experience with both successes and setbacks. We hope

Released online in J-STAGE as advance publication April 15, 2018.

*Address correspondence to:

Prof. Xu Qian, School of Public Health, Fudan University, Box 175, 138 Yi Xue Yuan Road, Shanghai 200032, China. E-mail:xqian@fudan.edu.cn these lessons will be useful to other low- and middleincome countries (LMICs) that still face daunting challenges in reducing their maternal and child mortality rates (3).

\section{The Evolution of China's MCH strategy}

China's achievement in improving $\mathrm{MCH}$ is based on its well-established policy framework. Figure 1 illustrates a timeline of major events and milestones in the development of China's MCH policies and initiatives since the 1980s. During the 1980s, a series of service standards, guidelines and regulations on $\mathrm{MCH}$ were developed and adopted, including the urban obstetric care quality standards and requirements (in 1980), the regulation of maternal and child health care (1986), and the regulation of maternal health care in rural areas (1989).

The 1990s witnessed a major shift in China's MCH strategy. In this period, the Chinese government made a number of commitments to international conventions related to the health and wellbeing of women and children, such as the Declaration on the Survival, Protection and Development of Children at the World Summit for Children (1990) and the Beijing Declaration and Action Plan at the 4th World Conference on Women 
Table 1. Key indicators of MCH in China from 1991-2014

\begin{tabular}{lrrrrr}
\hline Indicators & 1991 & 1995 & 2000 & 2005 & 2010 \\
\hline Infant mortality rate (deaths per 1,000 live births) & 50.2 & 36.4 & 32.2 & 19.0 & 13.1 \\
Under-5 mortality rate (deaths per 1,000 live births) & 61.0 & 44.5 & 39.7 & 22.5 & 16.4 \\
Maternal mortality ratio (deaths per 100,000 live births) & 80.0 & 61.9 & 53.0 & 47.7 & 30.0 \\
\hline
\end{tabular}

Source: World Bank

(1995). These international conventions provided China with opportunities to develop a policy framework aimed at improving $\mathrm{MCH}$ in China. China developed a series of laws, inter-connected strategies, and action plans, particularly the Action Plan of the China National Program for Children's Development (1992) and the China National Program for Women's Development (1995) (known as "Two Programs" in short). The Chinese government actively cooperated with international agencies to implement programs aimed at improving $\mathrm{MCH}$ status. These efforts established a strong foundation for the development of $\mathrm{MCH}$ in the 21 st century, particularly the much improved $\mathrm{MCH}$ service delivery system, which covers both urban and rural areas. The government introduced multiple strategies to reduce the financial burden for institutionbased childbirth, such as service price regulation, medical aid for the poor, reimbursement by health insurance, and direct subsidies (4).

\section{The key factors enabling policy implementation}

China's achievements in $\mathrm{MCH}$ are due in large part to defined policies and forceful implementation. Below we focus on several key determinants for successful policy implementation which we regard as major lessons of $\mathrm{MCH}$ promotion in China.

\subsection{Transforming political commitment into implementable policy and strategy}

The Chinese government's commitment to international goals (e.g., its commitment to achieving the health related Millennium Development Goals [MDGs]) provided an excellent opportunity for China to put $\mathrm{MCH}$ firmly on the government agenda (5), which facilitated the initiation of domestic policies (in the form of laws, regulations, and implementation guidelines) including the most important, "Two Programs". The "Two Programs" policy was developed with clear targets, timelines, and accountability. For example, the second "Two Programs" in 2001-2010 stated that the MMR should be reduced by one quarter by 2010 , using the MMR in $2000(53 / 100,000)$ as the baseline. With this set target, various policy approaches were adopted, such as boosting technical and financial capacity to improve $\mathrm{MCH}$, instituting the national "Jiang Xiao" Project to reduce MMR and eliminate neonatal tetanus, and promoting institutional childbirth.

\subsection{Setting a unified administrative system and strong accountability for policy implementation}

The unified, hierarchical administrative system in China helped to ensure the effective implementation and accountability of the policies defined by the central government throughout the country. Once specific $\mathrm{MCH}$ targets and their indicators have been set, the different levels of government, as responsible implementation agencies, have the obligation to ensure these targets are met in a specified timeframe. Poor performance would lead to a bad evaluation for the local governors, which in turn might (indirectly) affect their further political promotion. Moreover, $\mathrm{MCH}$ mortality surveillance systems were employed by provinces in order to reduce under-reported maternal deaths (6).

\subsection{Mobilizing key stakeholders}

Ultimately, actors are the key agents for transforming defined policies into practice. For example, the local government should adapt the national $\mathrm{MCH}$ policy into specific, localized action plans. Under the accountability system, the local government then has the motivation to put more effort and resources into $\mathrm{MCH}-$ related endeavors, in order to achieve the targets set in the national action plan. Other key actors are the frontline health workers. The government's commitment to improving $\mathrm{MCH}$, including its investment in health human resources, has greatly helped frontline health workers build their confidence and their willingness to conduct routine work. In addition, the strong sense of altruism shown by many $\mathrm{MCH}$ workers, particularly those from the remote rural areas, has also been an important factor in improving performance.

\section{The valuable lessons from China's experience for other low- and middle-income countries}

China has made great progress in $\mathrm{MCH}$, especially in improving maternal and child survival. Nevertheless, problems of regional disparities in $\mathrm{MCH}$ and suboptimal service coverage for migrant populations still need to be addressed (7). We believe that the Chinese experiences and practices of improving $\mathrm{MCH}$ over the past three decades may offer several key lessons for 


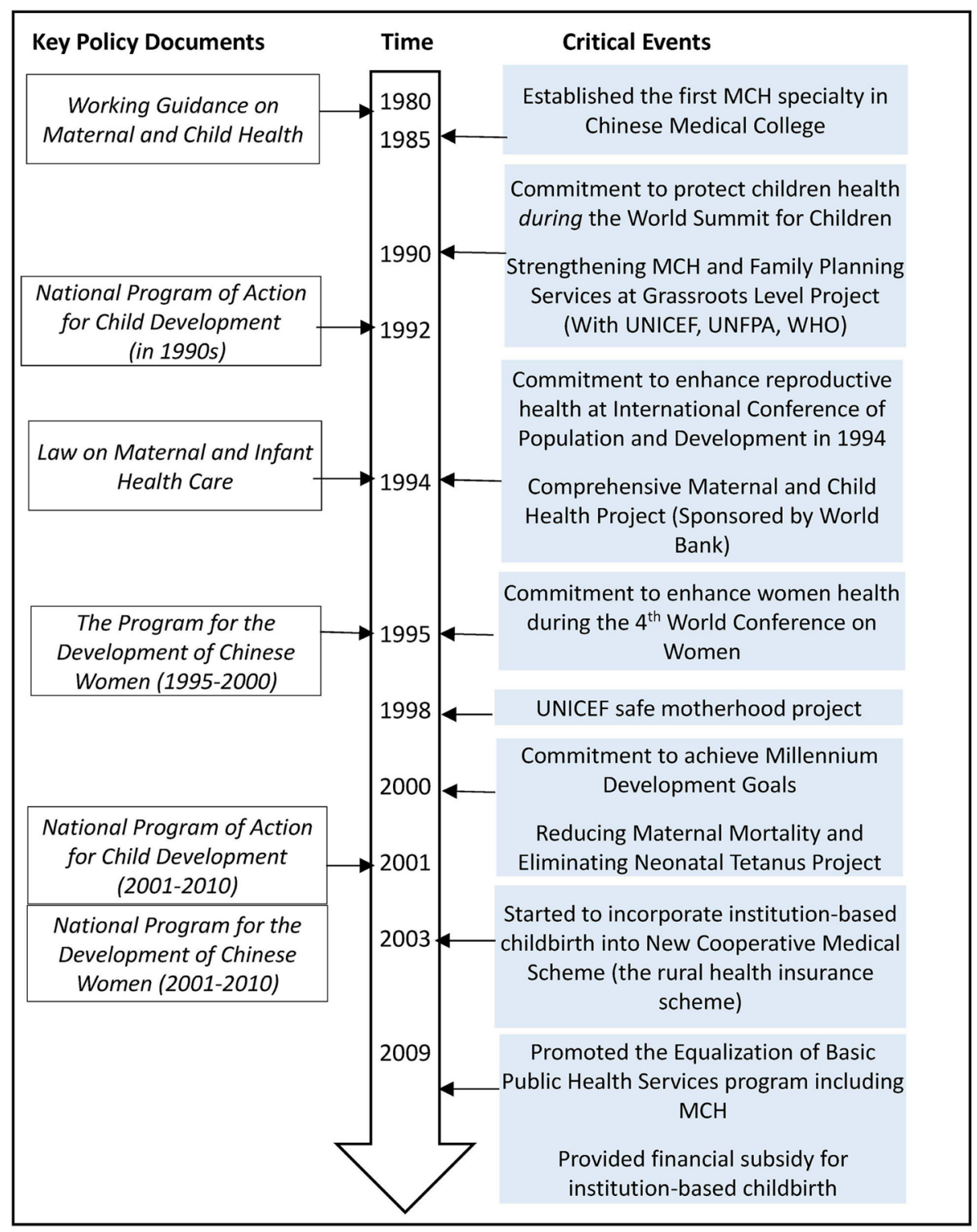

Figure 1. Brief timeline of China's MCH strategy since 1980.

other developing countries.

Government commitment to $\mathrm{MCH}$ The government commitment and political will to improve $\mathrm{MCH}$ placed it high on the national agenda and allowed $\mathrm{MCH}$ to be incorporated into national policy development. For example, the commitment made by the Chinese government to international conventions in the early 1990s greatly promoted the priority of $\mathrm{MCH}$ on the governmental agenda, compared with the 1980s. As a result, the decision makers at both national and local levels were pushed to take effective action to improve MCH. For LMICs, the Sustainable Development Goals (SDGs) provide a good opportunity to incorporate $\mathrm{MCH}$ into their own development strategies or governmental agendas. Such actions would give them the opportunity to access more resources for implementation, such as funding, personnel, and supplies, which $\mathrm{MCH}$ urgently needs.

Domestically driven approach The policy and practice of $\mathrm{MCH}$ in LMICs must have "national ownership", instead of being "donor driven". Programs should be domestically driven and designed around individual countries' political and social contexts, with support from the international donors. China used to be one of the largest recipients of health development cooperation. However, as shown in Figure 1, the financial and technical support from international donors has gradually given way to domestic funding and expertise, which has enhanced the existing health service delivery system, including $\mathrm{MCH}$. Moreover, with the successful implementation of the international aid program, more domestic funding was leveraged to co-finance $\mathrm{MCH}$ interventions in the long run. Nowadays, LMICs cooperate with many multilateral and bilateral health and development agencies, and it is necessary to make use of the external support to mobilize more domestic resources, and scale up implementation in a sustainable way.

Strong monitoring and accountability mechanism Effective health development cooperation programs 
rely on strong monitoring, evaluation and accountability mechanisms. In China, the monitoring and evaluation indicators written in the "Two Programs" played a key role in enhancing the $\mathrm{MCH}$ policy implementation. These indicators were not only acting as a means of supervision and monitoring for frontline health workers, but also as the performance assessment for local government incentives. Furthermore, more importance should be put on health information systems in order to provide reliable data to inform decisions.

Reaching the SDGs will be a long and difficult task for many LMICs. We hope that China's experience with $\mathrm{MCH}$ health policy design, action plan implementation, resource allocation, as well as monitoring and accountability can provide valuable lessons to help LMICs achieve the SDGs.

\section{Acknowledgements}

The authors appreciate the sponsor from ChinaUnited Kingdom (UK) Global Health Support Programme funded by UK Department for International Development.

\section{References}

1. Kuruvilla S, Schweitzer J, Bishai D, et al. Success factors for reducing maternal and child mortality. Bull World
Health Organ. 2014; 92:533-544.

2. World Health Organization. Success factors for women's and children's health: Policy and programme highlights from 10 fast-track countries. http://www.who.int/entity/ pmnch/knowledge/publications/success_factors highlights.pdf (accessed on February 26, 2018)

3. Liang J, Li X, Dai L, Zeng W, Li Q, Li M, Zhou R, He C, Wang Y, Zhu J. The changes in maternal mortality in 1000 counties in mid-Western China by a government-initiated intervention. PLoS One, 2012; 7:e37458.

4. Yang XG, Wang SS, Qian X, Multiple Measures to Alleviate Financial Burden of Facility-Based Childbirth, GHSP Project Policy brief, 2016 , http://cps.moh.gov. cn/website-webapp/ewebeditor/uploadfile/E07-OP1024(C2)\%20Multiple\%20Measures\%20to\%20Alleviate\%20 Financial\%20Burden\%20of\%20Fa-cility-Based\%20 Childbirth\%20\%20with\%20mark.pdf (accessed on Feb 26, 2018)

5. Unicef. Committing to child survival: A promise renewed. https://www.unicef.org/publications/files/APR_2015_9 Sep_15.pdf(accessed on February 26, 2018)

6. Kingdon JW. Agendas, alternatives, and public policies. Agendas, alternatives, and public policies. Little, Brown, Boston, USA, 1984; pp. 165-169.

7. Li Y, Zhang Y, Fang S, Liu S, Liu X, Li M, Liang H, Fu $\mathrm{H}$. Analysis of inequality in maternal and child health outcomes and mortality from 2000 to 2013 in China. Int J Equity Health. 2017; 16:66.

(Received March 2, 2018; Revised April 7, 2018; Accepted April 8, 2018) 